\title{
The Adoption of Social Media to Recruit Participants for the Cool Runnings Randomized Controlled Trial in Australia
}

Jacqueline D Burgess ${ }^{1,2,3}$, BA Comm; Roy M Kimble ${ }^{1,3,4}$, MD, MBChB; Kerrianne Watt ${ }^{5}$, BSc, PhD; Cate M Cameron ${ }^{6}$, $\mathrm{PhD}, \mathrm{MPH}, \mathrm{BSocWk}$

\footnotetext{
${ }^{1}$ Centre for Children's Burns and Trauma Research, University of Queensland, South Brisbane, Australia

${ }^{2}$ Wound Management Innovation Cooperative Research Centre, Brisbane, Australia

${ }^{3}$ Pegg Leditschke Children's Burns Centre, Lady Cilento Childen's Hospital, Brisbane, Australia

${ }^{4}$ Urology Burns \& Trauma Unit, Department of Paediatric Surgery, Lady Cilento Children's Hospital, Brisbane, Australia

${ }^{5}$ College of Public Health, Medical and Veterinary Sciences, James Cook University, Townsville, Australia

${ }^{6}$ The Hopkins Centre, Menzies Health Institute Queensland, Griffith University, Meadowbrook, Australia
}

\section{Corresponding Author:}

Jacqueline D Burgess, BA Comm

Centre for Children's Burns and Trauma Research

University of Queensland

Centre for Child Health Research

Level 7, 62 Graham Street

South Brisbane, Queensland

Australia

Phone: 61407789078

Email: jacquii@uq.edu.au

\section{Abstract}

Background: Using social media to recruit specific populations for research studies is gaining popularity. Given that mothers of young children are the most active on social media, and young children are the most at risk of preventable burn injuries, social media was used to recruit mothers of young children to a burn prevention intervention.

Objective: The aim of this paper was to describe the social media recruitment methods used to enroll mothers of young children to the app-based burn prevention intervention Cool Runnings.

Methods: Participants were recruited via paid Facebook and Instagram advertisements to a 2-group, parallel, single-blinded, randomized controlled trial (RCT). The advertisements were targeted at women 18 years and older, living in Queensland, Australia, with at least 1 child aged 5 to 12 months at the time of recruitment.

Results: Over the 30-day recruitment period from January to February 2016, Facebook and Instagram advertisements reached 65,268 people, generating 2573 link clicks, 1161 app downloads, and 498 enrolled participants to the Cool Runnings RCT. The cost per enrolled participant was Aus \$13.08. Saturdays were the most effective day of the week for advertising results. The most popular time of day for enrolments was between 5 to 11 PM. This recruitment strategy campaign resulted in a broad reach of participants from regional, rural, and remote Queensland. Participants were representative of the population in regard to age and education levels.

Conclusions: To our knowledge, this is the first use of social media recruitment for an injury prevention campaign. This recruitment method resulted in the rapid and cost-effective recruitment of participants with social, geographic, and economic diversity that were largely representative of the population.

(JMIR Res Protoc 2017;6(10):e200) doi: 10.2196/resprot.8189

\section{KEYWORDS}

social media; online recruitment; burn prevention; methods, randomized controlled trial 


\section{Introduction}

More than half of the world's population now has access to the Internet, and 2.8 billion people actively use social media [1]. Social media has become an integral part of modern society. It is more than just a place for friends to connect socially; it is used for politics, education, entertainment, shopping, and health. While commercial companies were quick to see the potential of social media to reach and interact with large targeted populations, researchers were slow adopters. Increasingly, social media platforms, such as Facebook, are being used to recruit participants for health and medical research $[2,3]$.

Facebook's ability to target advertising to specific demographics from its diversity of users offers researchers an opportunity to recruit populations that can be hard to access via traditional recruitment methods, including economically disadvantaged and geographically remote populations $[3,4,5]$. Globally, social media users have increased by $21 \%$ since January 2016 [1]. Facebook alone has 2 billion monthly users [6]. In Australia, approximately $70 \%$ of the population actively uses Facebook and the largest demographic are women aged 25 to 34 years [5]. Mothers with children under 5 years of age are the most active on social media [5,7].

Burns are the 5th most common cause of non-fatal childhood injuries globally [8]. Most burns to children under the age of 4 are scalds, predominantly from hot beverages [9-11]. In Australia, hot beverage scalds account for 1 in 5 burns to children - a figure that has remained the same for the past 15 years [9]. Added to this issue is the low use of correct burn first aid at the scene, despite strong evidence that burn first aid applied within 3 hours of the burn occurring provides pain relief and leads to less scarring, fewer surgical interventions, and shorter hospital stays [12]. Beyond the pain, itching, and scarring that can result from these injuries, there are also the long-term effects burns take on both the child and family. The frequent hospital visits/admissions for ongoing scar management, coping with changes in appearance, and people's reaction to the scar can lead to social and psychological problems. There are also financial costs both to the family when parents take time off work to care for the injured child and their continuing rehabilitation needs and the cost to the healthcare system. In the United Kingdom, they have reported the cost of treating a minor scald as $£ 1850$ (US \$2400) [13]. In children, this figure is higher as scar management and surgical procedures continue until they stop growing.

The high physical, emotional, and financial burdens associated with hot beverage scalds make it an important public health issue. Increasing awareness regarding burn severity and frequency of hot beverage scalds, as well as correct burn first aid, is an important step in reducing the burden of this injury [14-16]. To date, public health interventions and injury prevention are areas where technology has been underutilized.

In light of the popularity of social media in mothers of young children and evidence of social media's broad reach, cost efficiencies, and capacity for targeting specific populations, social media was used to recruit mothers to the app-based burn prevention intervention Cool Runnings. The Cool Runnings app was used as the channel for delivering the 2-group, parallel, single-blinded, randomized controlled trial (RCT) over the 6-month intervention period (described in detail elsewhere). The purpose of this paper was to describe the use of social media as a tool for recruiting mothers of young children to this RCT.

\section{Methods}

\section{Participants}

Participants were recruited over a 30-day period for a 2-group, parallel, single-blinded RCT-Cool Runnings-aimed at changing knowledge about burn risks and correct burn first aid treatment in mothers of young children. The protocol for this study was published previously [17]. The inclusion criteria for this study were females aged 18 years and older with at least 1 child aged 5 to 12 months, who owned a mobile phone, and resided in the state of Queensland, Australia. Participants were recruited through Facebook and Instagram advertisements between January and February 2016. The state of Queensland is $1,852,642 \mathrm{~km}^{2}$ (approximately $2 \frac{1}{2} 2$ times the size of Texas, or 3 times the size of France) with a population of 4.9 million.

\section{Facebook Recruitment}

Facebook and Instagram advertisements were directed to the target group described above. Facebook's Audience Insights tool was used to better understand the social and psychological triggers of the target group. Demographic filtering showed the audiences "liked" pages, lifestyle factors, education, job titles, and frequency of activities, and this information informed the approach, messaging, and strategies for recruitment on the 2 platforms. Targeted, persuasive ad copy was developed for the Facebook and Instagram advertisements. Ad sets used 2 message themes: incentive-based and emotive-based. The incentive-based messages leveraged the ability to earn rewards and win prizes to drive recruitment. An example of one of the incentive-based messages is shown in Figure 1. The emotive-based messages created an emotional response in potential participants and called out the "greater good" of participating in a study aimed at keeping children safe. An example of an emotive-based message is:

21 children die each week in Australia from
preventable injuries! Thousands more are
hospitalized. With your help we can reduce this.
Download the Cool Runnings app and learn ways to
protect your child and other children from
preventable injuries.

Altruistic and incentive-based messages are recognized as influential motivators in behavioral studies $[18,19]$. Messages that arouse emotions in potential participants and make an impact are more likely to get their attention and motivate them to take action [20]. These messages also aimed to raise mothers' awareness of the threat of injuries in young children, combined with an efficacy component to learn how to prevent these injuries. Messages that combine threat and self-efficacy components are more effective than just threat and/or fear based messages [21].

A total of 45 advertisement sets were developed, each containing different combinations (ie, device type, visual elements, message 
theme, and ad placement). The variables tested were Apple (iOS) versus Android, video versus photo versus carouse, emotive versus incentive, and Facebook mobile newsfeed versus Instagram advertisement.
In total, 32 adaptations of the advertising copy were divided across the variables listed above. From the advertisements, interested individuals could click on an embedded link taking them directly to the Cool Runnings app in the Google Play or Apple App Store.

Figure 1. Example incentive-based recruitment advertisement used on Facebook.

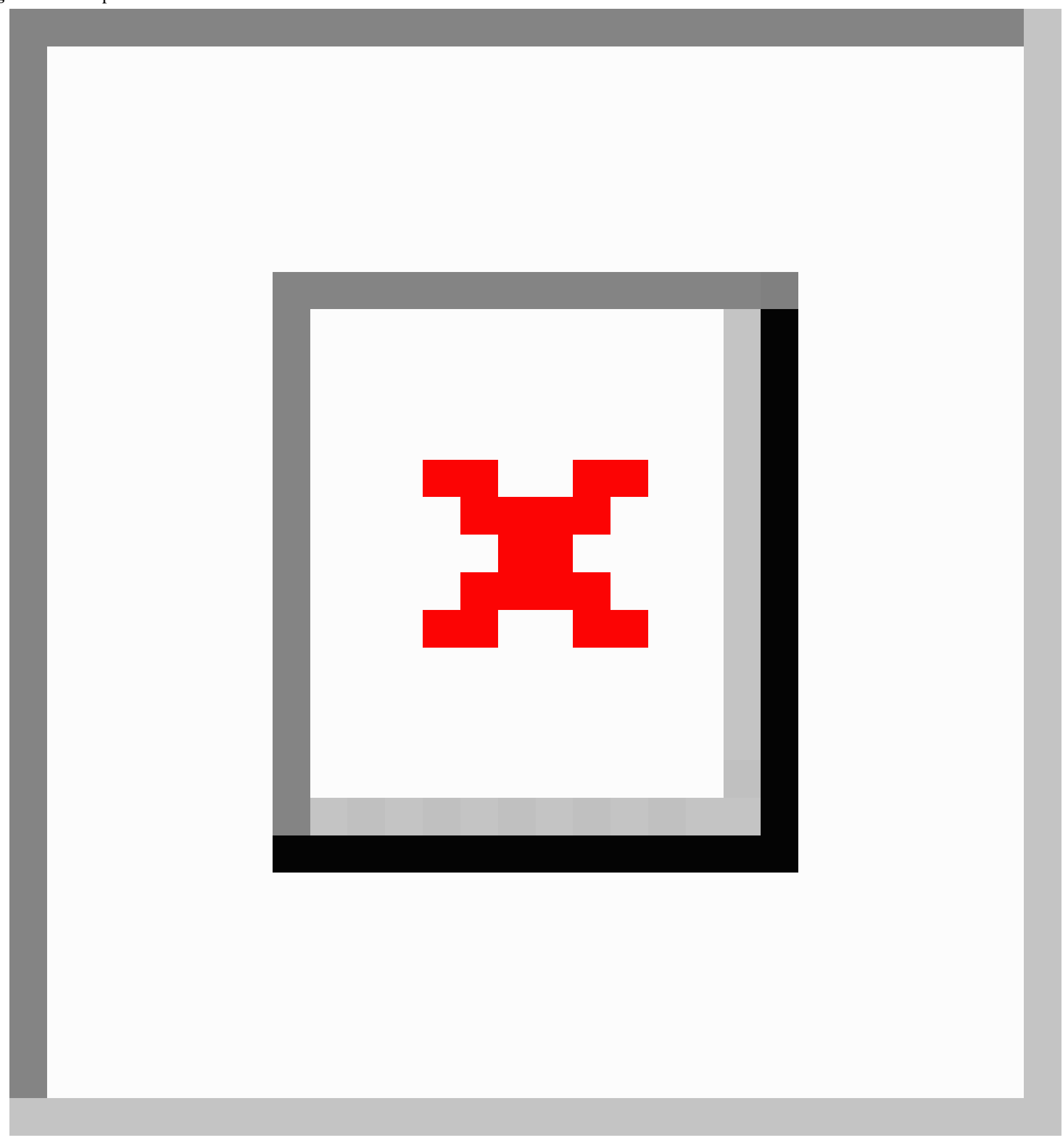

\section{Outcome Measures}

Instagram is owned by Facebook, which allows the management of advertising campaigns and/or ad placement on both platforms from Facebook Ads Manager portal. This portal provides the following advertisement metrics: (1) impressions, number of times ads were shown; (2) reach, number of individual people who saw the ads; (3) link clicks, number of people who saw the ad and clicked through to download the app; (4) video views, number of times video viewed for 3 seconds or more; and (5) costs per 1000 impressions, per reach, per link click.

The number of Apple and Android app downloads resulting from the advertisement link clicks and the subsequent individuals who consented to participate in the study were calculated to determine the cost per participant. 


\section{Study Enrollment}

Once the app was downloaded, individuals were provided with additional information about the study and given the opportunity to consent to participate. Participants completed a 19-item questionnaire detailing demographic factors (such as education level, age of youngest child, number of children, marital status, and smoking status) and level of child burn risk knowledge and burn first aid knowledge. Participants also recorded their postcode, which was later recoded using Accessibility/Remoteness Index in Australia (ARIA) 2011 data, developed by the National Center for the Social Applications of Geographic Information Systems into the categories major cities, inner/outer regional, and remote/very remote [22].

\section{Ethics Approval}

This study was approved by the University of Queensland Institutional Human Research Ethics Committee (approval number: 2015001652).

\section{Results}

During the 30-day recruitment period, 498 participants were recruited to the Cool Runnings study through Facebook and Instagram advertisements.

\section{Participant Demographics}

The demographic characteristics of recruited participants compared with mothers who birthed in Queensland in 2015 (the year the study was conducted), derived from the Queensland Perinatal Data Collection Report 2015 [23] is shown in Table 1. While statistical comparisons were not possible, these data indicated that participants recruited for this study were similar to the target population (mothers who gave birth in Queensland) on most characteristics (age group, marital status, country of birth, first-time mother), except smoking status. No comparable data were available for education level or ARIA. The location of usual residence was categorized using ARIA, developed by the National Center for the Social Applications of Geographic Information Systems. Each geographical area was allocated a score between 0 and 15, based on the (road) distance to nearby towns that provide services [24]. Scores were then allocated to the following categories: urban (major city: 0.0 to 0.2 ); peri-urban (inner regional: 0.2 to 2.4 ; outer regional: 2.4 to 5.92); and remote (remote: 5.92 to 10.53 ; very remote: 10.53 and greater). The broad reach of study participants is highlighted in Figure 2. 
Table 1. Demographic characteristics of recruited participants (N=498) and Queensland population data for mothers in 2015.

\begin{tabular}{|c|c|c|}
\hline Characteristic & Recruited participants, n (\%) & Queensland mothers, $\mathrm{n}(\%)$ \\
\hline \multicolumn{3}{|l|}{ Age } \\
\hline $18-24$ years & $89(17.9 \%)$ & $20 \%$ \\
\hline $25-29$ years & $176(35.4 \%)$ & $28 \%$ \\
\hline $30-34$ years & $161(32.3 \%)$ & $32 \%$ \\
\hline $35-39$ years & $62(12.4 \%)$ & $16 \%$ \\
\hline $40+$ years & $10(2.0 \%)$ & $4 \%$ \\
\hline First-time mothers & $216(43.4 \%)$ & $41 \%$ \\
\hline \multicolumn{3}{|l|}{ Marital status } \\
\hline Married/defacto & $416(83.5 \%)$ & $84 \%$ \\
\hline Single & $67(13.5 \%)$ & $14 \%$ \\
\hline Separated/divorced & $13(2.6 \%)$ & $1.4 \%$ \\
\hline Current smoker & $97(19.5 \%)$ & $12 \%$ \\
\hline \multicolumn{3}{|l|}{ Country of birth } \\
\hline Australia & $419(84.1 \%)$ & $74 \%$ \\
\hline New Zealand & $23(4.6 \%)$ & $5 \%$ \\
\hline United Kingdom & $23(4.6 \%)$ & $3 \%$ \\
\hline Other & $33(6.6 \%)$ & $18 \%$ \\
\hline Highest education level & & N/A \\
\hline Less than Year 12 & $86(17.3 \%)$ & \\
\hline Year 12 completion & $131(26.3 \%)$ & \\
\hline Advanced diploma/trade certificate & $127(25.5 \%)$ & \\
\hline University degree & $112(22.5 \%)$ & \\
\hline Post-graduate degree & $42(8.4 \%)$ & \\
\hline ARIA $^{a}$ & & N/A \\
\hline Urban (major cities) & $238(47.8 \%)$ & \\
\hline Peri-urban (inner/outer regional) & $205(41.2 \%)$ & \\
\hline Remote/very remote & $49(9.8 \%)$ & \\
\hline
\end{tabular}

${ }^{\mathrm{a}}$ ARIA: Accessibility/Remoteness Index of Australia. 
Figure 2. Map of Queensland (area 1,852,642 $\mathrm{km}^{2}$ ), Australia, showing the broad reach of study participants (marked by pins).

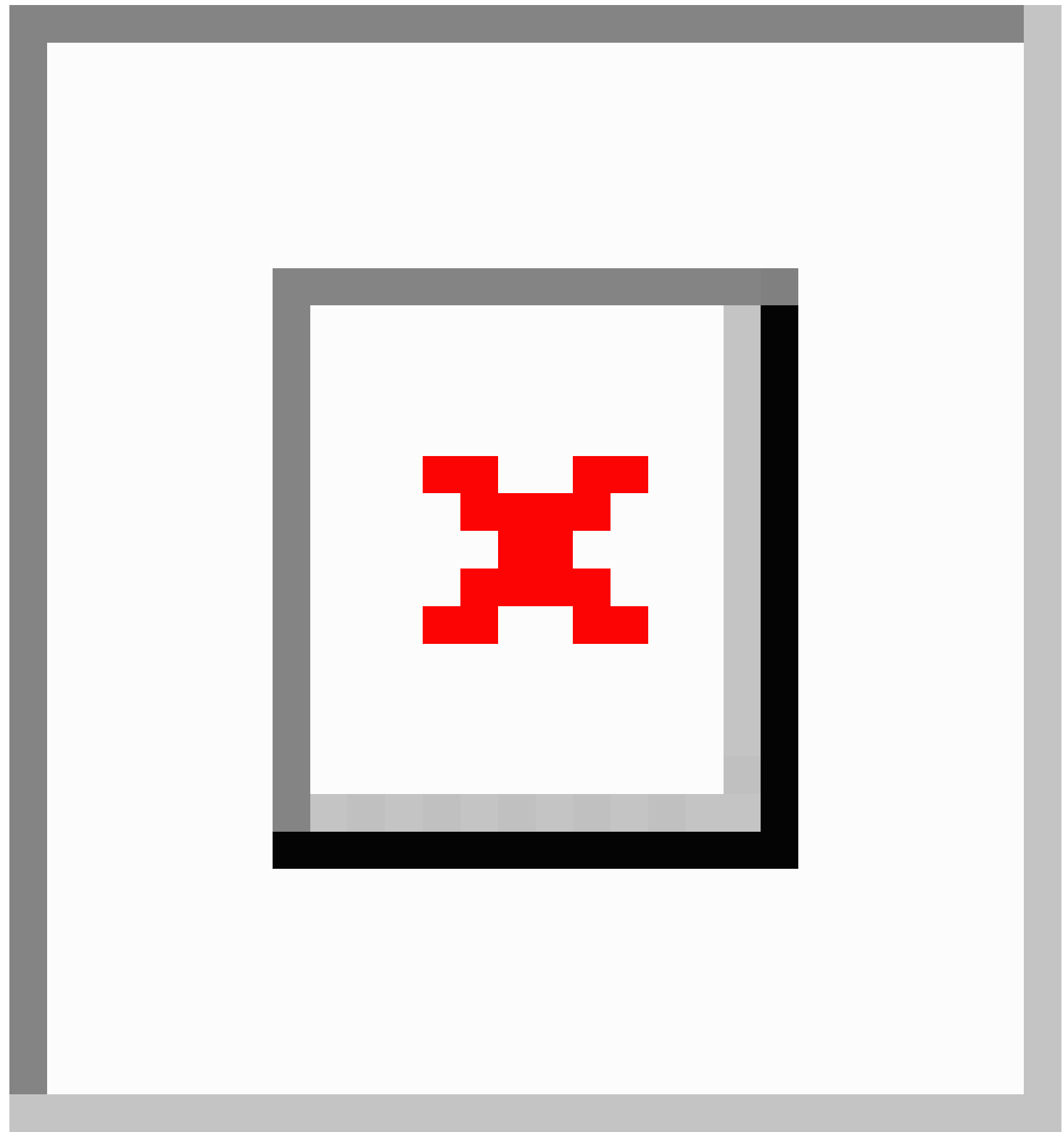

\section{Facebook Recruitment Outcomes}

Facebook and Instagram advertisements generated 420,402 impressions and reached 65,268 people, generating 2573 link clicks and 1161 app downloads. There were 291 post reactions (like, love, etc.), 61 comments, and 164 shares. The cost of advertisements (ads) per 1000 impressions was Aus \$16.39, per 1000 people reached Aus $\$ 105.40$, and per recruited participant Aus \$13.08. The recruitment process from ad impressions through to recruited participant is shown in Figure 3. Based on data from App Annie (San Francisco, USA), an industry standard app ranking and analytics company [25], in February 2016 the Cool Runnings app ranked number 48 in Australia for all educational app downloads.
Of the 45 ad sets, $22(49 \%, 22 / 45)$ were emotive-based (12 [55\%, 12/22] videos, 6 [27\%, 6/22] images, 4 [18\%, 4/22] carousel), $16(36 \%, 16 / 22)$ were incentive-based $(6[38 \%, 6 / 16]$ videos, $6[38 \%, 6 / 16]$ images, 4 [25\%, 4/16] carousel), and the remainder used mixed themes. Two emotive-based video ads were the most effective, resulting in $72.1 \%$ (359/498) of all participants recruited. Saturdays were the most effective day of the week for participant enrollment, and 5 to $11 \mathrm{PM}$ was the most popular time of day with $55.0 \%$ (274/498) of enrollments occurring during these hours. The effect of advertisement optimization during each day of the recruitment period is shown in Figure 4. Once the advertisements started to be ineffective they were cut and the budget placed on the advertisements that were performing well. 
Thirty-two adaptations of the ad copy were developed based on the variables listed earlier and split-tested. In the first 3 days of recruitment, 40 participants were recruited from 18 of the 32 adaptations. The advertisements that did not resonate with the targeted audience were removed and the budget reallocated to the advertisements that were performing well. This process was repeated until just 2 advertisements remained-both emotive-based videos on iOS and Android. The remaining budget was then allocated to these 2 advertisements. Individuals were removed from the advertising audience once they had been recruited. This saved advertising budget and stopped participants from continually seeing the recruitment messages. This ability to access Facebook's analytics and real-time reports on the effectiveness of different images, message themes, and message wording allowed more effective and efficient use of time and resources.

Figure 3. Flowchart of the recruitment process from Facebook impressions to recruited participants .

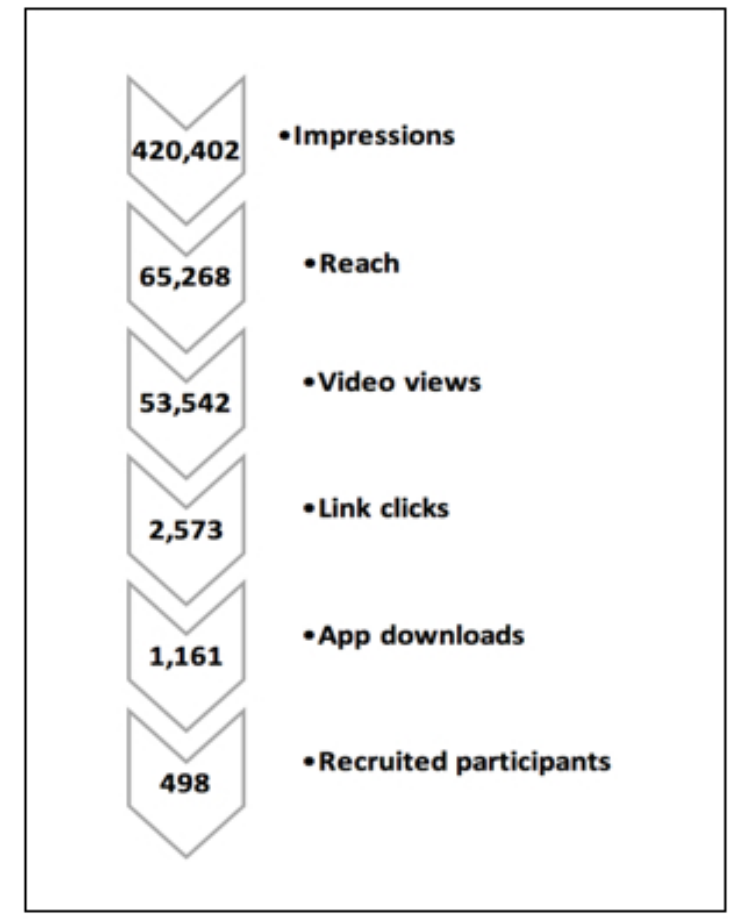


Figure 4. Number of participants enrolled each day of the 30-day recruitment period.

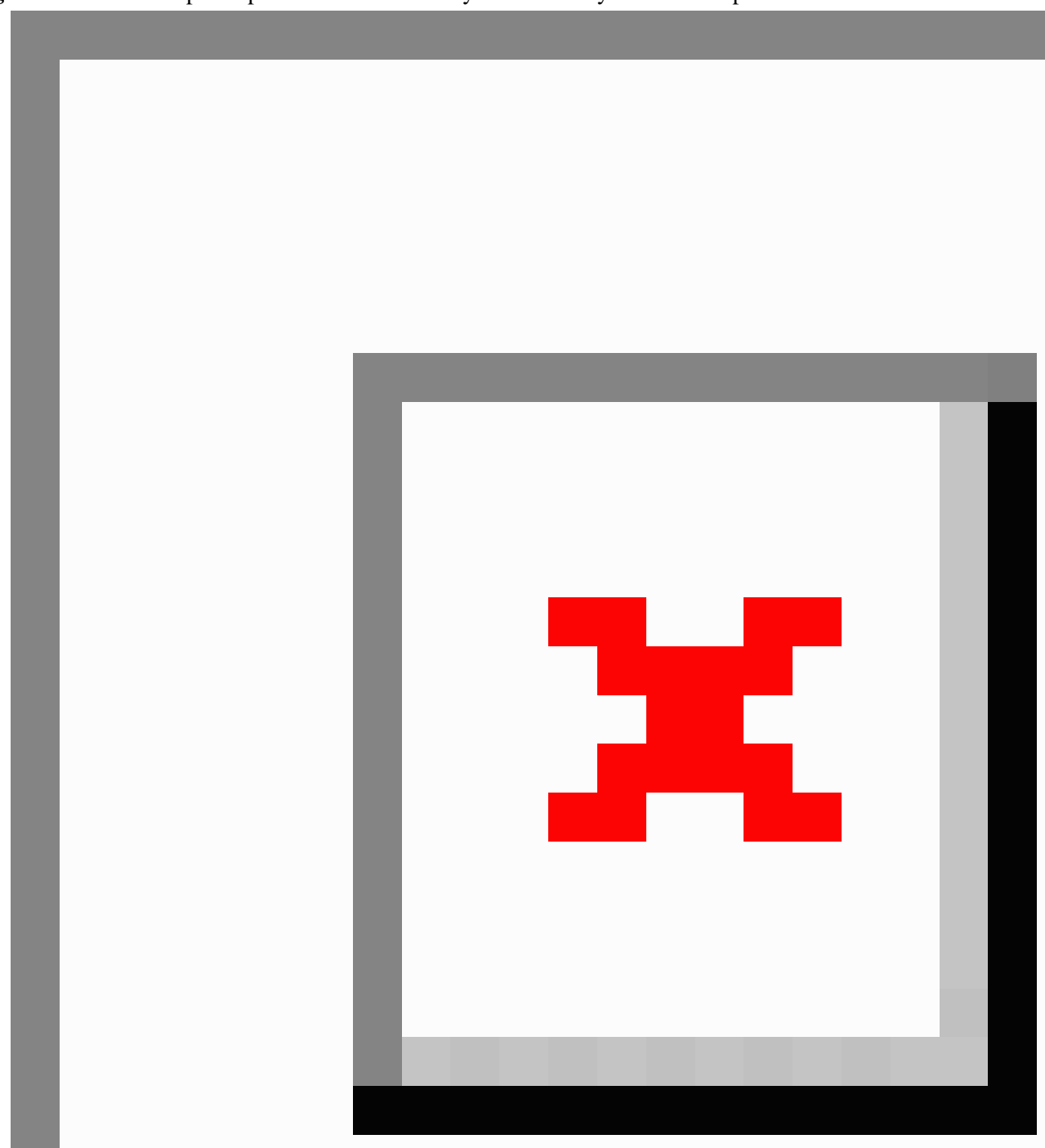

\section{Discussion}

Recruiting 498 eligible participants in 30-days for less than Aus $\$ 14$ per participant demonstrated that recruiting using Facebook's targeted paid advertising on its 2 platforms (Facebook and Instagram) is an efficient and cost effective method for recruiting mothers of young children to public health research programs.

\section{Targeted Advertisements}

For this method of recruitment to be effective it is important to first understand how the targeted audience uses social media and what social media platforms are they using.
Facebook is the most widely used of the major social media platforms and its user base is most broadly representative of the population as a whole across age and gender [26,27]. However, it is important to note that some social media platforms are more popular among certain demographics. For example, in Australia Twitter is more popular among males and Pinterest is more popular among females; adults under 30 years prefer Instagram and Snapchat, while LinkedIn is more popular among older adults [28]. For targeting millennial mothers, Facebook and Instagram were an ideal choice given mothers active daily use on these platforms. 


\section{Reach, Representativeness, and Cost}

Accessibility to Facebook and Instagram's large and diverse users address one of the challenges facing many research projects when it comes to recruiting-adequate size and representativeness of sample. The literature confirms targeted Facebook advertising has been effective in recruiting populations based on geographic location, age, and gender, but also specific, often hard-to-reach populations [29-31]. Mothers of young children were the focus of this recruitment strategy and are the most active users on Facebook [6,7]. The targeted advertisements for this study delivered participants from a variety of socio-economic, geographic, and educational backgrounds. There was good representation of mothers across the age groups and an almost equal split of premipara (first-time mothers) and multipara participants. These participants were largely representative of the target population (women who birthed in Queensland in 2015) with regard to age, marital status, being a first-time mother, and country of birth [23].

While the participants for this study were well represented on Facebook, Instagram, and many other social media platforms, it is important to note there are populations that are not so well represented on social media, such as older, economically disadvantaged, rural/remote, and less educated individuals [2]. However, research by the Pew Institute [32] shows these trends are changing. These issues and limitations also affect traditional recruitment samples.

A number of studies have compared social media recruitment with traditional recruitment methods in terms of cost and speed, with the majority showing social media to be more effective for both [2,33]. However, a review of 30 studies that compared social media with other recruitment methods reported only 12 $(40 \%, 12 / 30)$ found social media to be the best recruitment method overall [3]. Social media recruitment is reported to be better for recruiting hard-to-reach populations. A systematic review by Thornton et al [2] reported the average cost per enrolled participant using Facebook recruitment was US \$17 (range $\$ 1.36$ to $\$ 110$ ). Traditional recruitment methods can cost US \$20 to \$500 per participant, depending on the strategy and target population [34-36].

\section{Limitations}

This recruitment strategy had some limitations. The social nature of Facebook increases the likelihood of snowballing, with individuals sharing the study advertisements with their Facebook friends, potentially leading to sampling bias. Another limitation is relying on information individuals provide on their Facebook and/or Instagram profile, which may not be correct or up-to-date. Some interested individuals who received the targeted advertisements were not eligible for recruitment as they no longer lived in Queensland but had not updated their profile information. Because some of the baseline questions for Cool Runnings were to determine knowledge about burn risks to children, we were unable to mention burn prevention to children specifically in the advertisements. This may have led to confusion in interested individuals. Finally, the initial advertisement sets did not specify that participants had to have at least 1 child aged between 5 to 12 months. This led to some interested individuals downloading the app and then finding they were ineligible once they read the participant information/consent page. This issue was rectified in the second week of recruitment.

To our knowledge, this is the first use of social media recruitment for an injury prevention campaign. Based on the reach, representativeness, cost, and speed of social media recruitment for this study, and as reported in the literature, this recruitment method would be beneficial for recruiting targeted populations at risk of specific injuries. It also has great potential for public health campaigns that want to reach and engage large numbers of people, whether it is to promote healthy behaviors, prevent disease, or reduce injuries.

\section{Conclusions}

Recruiting via social media allowed a rapid and cost-effective recruitment of mothers of young children to an injury prevention campaign. The social, geographical, and economic diversity of the recruited participants demonstrates the power of social media recruitment as a positive option for studies needing to recruit hard-to-reach populations or representative study samples.

\section{Acknowledgments}

The authors acknowledge and thank Lyndon Holzheimer and Benjamin Ruane from iPug Pty Ltd for strategic and technical support with social media recruitment implementation. JB would like to acknowledge the support of the Australian Government's Cooperative Research Centers Program.

\section{Conflicts of Interest}

None declared.

\section{References}

1. Kemp S. We Are Social. 2017 Jan 24. Digital in 2017: global overview URL: https://wearesocial.com/special-reports/ digital-in-2017-global-overview [accessed 2017-06-08] [WebCite Cache ID 6r4tjN9Hi]

2. Thornton L, Batterham PJ, Fassnacht DB, Kay-Lambkin F, Calear AL, Hunt S. Recruiting for health, medical or psychosocial research using Facebook: Systematic review. Internet Interv 2016 May;4:72-81. [doi: 10.1016/j.invent.2016.02.001]

3. Topolovec-Vranic J, Natarajan K. The use of social media in recruitment for medical research studies: a scoping review. J Med Internet Res 2016 Nov 07;18(11):e286 [FREE Full text] [doi: 10.2196/jmir.5698] [Medline: 27821383] 
4. Cowling D. Social Media News. 2017 Apr 01. Social media statistics Australia - March 2017 URL: https://www. socialmedianews.com.au/social-media-statistics-australia-march-2017/ [accessed 2017-06-08] [WebCite Cache ID $\underline{6 r 4 t 7 r K m A}]$

5. Duggan M, Lenhart A, Lampe C, Ellison NB. Pew Research Center - Internet and Technology. Washington, DC: Pew Research Center; 2015 Jul 16. Parents and social media URL: http://www.pewinternet.org/2015/07/16/ parents-and-social-media/ [accessed 2017-06-09] [WebCite Cache ID 6r4xhOosl]

6. Statista. Number of Facebook users worldwide 2008-2017 URL: https://www.statista.com/statistics/264810/ number-of-monthly-active-facebook-users-worldwide/ [accessed 2017-06-09] [WebCite Cache ID 6r6BWbhrt]

7. Sify News. 2013 Nov 06. Mothers with children under 5 most active on social media URL: http://www.sify.com/news/ mothers-with-children-under-5-most-active-on-social-media-news-international-nlgna6jiccesi.html [accessed 2017-06-09] [WebCite Cache ID 6r4xyryTb]

8. World Health Organization. Media Center. 2017 Aug. Burns URL: http://www.who.int/mediacentre/factsheets/fs365/en/ [accessed 2017-05-12] [WebCite Cache ID 6r7y1DtKb]

9. Burgess JD, Kimble RM, Cameron CM, Stockton KA. Hot beverage scalds in Australian children: still simmering 10 years on. J Burn Care Res 2016;37(4):e335-e339. [doi: 10.1097/BCR.0000000000000267] [Medline: 26132050]

10. Dewar DJ, Magson CL, Fraser JF, Crighton L, Kimble RM. Hot beverage scalds in Australian children. J Burn Care Rehabil 2004;25(3):224-227. [Medline: 15273461]

11. Riedlinger DI, Jennings PA, Edgar DW, Harvey JG, Cleland MH, Wood FM, et al. Scald burns in children aged 14 and younger in Australia and New Zealand-an analysis based on the Burn Registry of Australia and New Zealand (BRANZ). Burns 2015 May;41(3):462-468. [doi: 10.1016/j.burns.2014.07.027] [Medline: 25440854]

12. Wood FM, Phillips M, Jovic T, Cassidy JT, Cameron P, Edgar DW, Steering Committee of the Burn Registry of AustraliaNew Zealand (BRANZ). Water first aid is beneficial in humans post-burn: evidence from a bi-national cohort study. PLoS One 2016;11(1):e0147259 [FREE Full text] [doi: 10.1371/journal.pone.0147259] [Medline: 26808839]

13. Making the Link: Child Accident Prevention Trust. 2012 Aug. The costs of hot drink scalds URL: http://www. makingthelink.net/tools/costs-child-accidents/costs-hot-drink-scalds [accessed 2017-06-10] [WebCite Cache ID 6r7yG5SAf]

14. The IFORCCS. International Federation of Red Cross and Red Crescent Societies. 2010. First aid for a safer future: updated global edition. Advocacy report 2010 URL: http://www.ifrc.org/PageFiles/53459/

First $\% 20$ aid $\% 20$ for $\% 20$ a $\% 20$ safer $\% 20$ future $\% 20$ Updated $\% 20$ global $\% 20$ edition $\% 20 \% 20$ Advocacy $\% 20$ report $\% 202010 \% 20(2)$. pdf?epslanguage =en [accessed 2017-05-12] [WebCite Cache ID 6sgpbl4JU]

15. Mytton JA, Towner EM, Kendrick D, Stewart-Brown S, Emond A, Ingram J, et al. The First-aid Advice and Safety Training (FAST) parents programme for the prevention of unintentional injuries in preschool children: a protocol. Inj Prev 2014 Feb;20(1):e2. [doi: 10.1136/injuryprev-2012-040689] [Medline: 23302145]

16. Macarthur C. Evaluation of Safe Kids Week 2001: prevention of scald and burn injuries in young children. Inj Prev 2003 Jun;9(2):112-116 [FREE Full text] [Medline: 12810735]

17. Burgess JD, Cameron CM, Watt K, Kimble RM. Cool Runnings - an app-based intervention for reducing hot drink scalds: study protocol for a randomised controlled trial. Trials 2016 Aug 03;17(1):388 [FREE Full text] [doi: 10.1186/s13063-016-1521-z] [Medline: 27488411]

18. Oh S. The characteristics and motivations of health answerers for sharing information, knowledge, and experiences in online environments. J Am Soc Inf Sci 2011 Nov 01;63(3):543-557. [doi: 10.1002/asi.21676]

19. Mitchell M, White L, Oh P, Alter D, Leahey T, Kwan M, et al. Uptake of an incentive-based mHealth app: process evaluation of the Carrot Rewards app. JMIR Mhealth Uhealth 2017 May 30;5(5):e70 [FREE Full text] [doi: 10.2196/mhealth.7323] [Medline: 28559224]

20. Opel DJ, Diekema DS, Lee NR, Marcuse EK. Social marketing as a strategy to increase immunization rates. Arch Pediatr Adolesc Med 2009 May;163(5):432-437. [doi: 10.1001/archpediatrics.2009.42] [Medline: 19414689]

21. Stephenson MT, Witte K. Fear, threat, and perceptions of efficacy from frightening skin cancer messages. Public Health Rev 1998;26(2):147-174. [Medline: 10327830]

22. Hugo Centre for Migration and Population Research. ARIA and accessibility URL: http://www.adelaide.edu.au/apmrc/ research/projects/category/aria.html [accessed 2017-05-29] [WebCite Cache ID 6rBw4EMIV]

23. Queensland Health. Queensland Perinatal Data Collection. 2015. Perinatal statistics 2015 annual report URL: https://www. health.qld.gov.au/hsu/peri/peri2015/report2015 [accessed 2017-08-09] [WebCite Cache ID 6sgk0G3r0]

24. Queensland Government Statisticians Office. Accessibility and remoteness index of Australia URL: http://www. qgso.qld.gov.au/about-statistics/statistical-standards/national/aria.php [accessed 2017-08-14] [WebCite Cache ID 6siPGs4sI]

25. App Annie. URL: https://www.appannie.com/en/ [accessed 2017-06-11] [WebCite Cache ID 6r7yVWUjL]

26. Gosling SD, Vazire S, Srivastava S, John OP. Should we trust web-based studies? A comparative analysis of six preconceptions about internet questionnaires. Am Psychol 2004;59(2):93-104. [doi: 10.1037/0003-066X.59.2.93] [Medline: $\underline{14992636]}$

27. Schwartz HA, Eichstaedt JC, Kern ML, Dziurzynski L, Ramones SM, Agrawal M, et al. Personality, gender, and age in the language of social media: the open-vocabulary approach. PLoS One 2013;8(9):e73791 [FREE Full text] [doi: 10.1371/journal.pone.0073791] [Medline: 24086296] 
28. Sensis Social Media Report 2016. 2016 Jun 01. How Australian people and businesses are using social media URL: https:/ /www.sensis.com.au/asset/PDFdirectory/Sensis Social Media Report 2016.PDF [accessed 2017-05-01] [WebCite Cache ID 6r7ylVguF]

29. Subasinghe AK, Nguyen M, Wark JD, Tabrizi SN, Garland SM. Targeted Facebook advertising is a novel and effective method of recruiting participants into a human papillomavirus vaccine effectiveness study. JMIR Res Protoc 2016 Jul 22;5(3):e154 [FREE Full text] [doi: 10.2196/resprot.5679] [Medline: 27450586]

30. Kayrouz R, Dear BF, Karin E, Titov N. Facebook as an effective recruitment strategy for mental health research of hard to reach populations. Internet Interv 2016 May;4:1-10. [doi: 10.1016/j.invent.2016.01.001]

31. Martinez O, Wu E, Shultz AZ, Capote J, López RJ, Sandfort T, et al. Still a hard-to-reach population? Using social media to recruit Latino gay couples for an HIV intervention adaptation study. J Med Internet Res 2014 Apr 24;16(4):e113 [FREE Full text] [doi: 10.2196/jmir.3311] [Medline: 24763130]

32. Perrin A. Pew Research Center Internet and Technology. Washington, DC: Pew Research Center; 2015 Oct 08. Social media usage 2005-2015 URL: http://www.pewinternet.org/2015/10/08/social-networking-usage-2005-2015/ [accessed 2017-05-01] [WebCite Cache ID 6r7zP4xk2]

33. Shere M, Zhao XY, Koren G. The role of social media in recruiting for clinical trials in pregnancy. PLoS One 2014;9(3):e92744 [FREE Full text] [doi: 10.1371/journal.pone.0092744] [Medline: 24671210]

34. Robinson JL, Fuerch JH, Winiewicz DD, Salvy SJ, Roemmich JN, Epstein LH. Cost effectiveness of recruitment methods in an obesity prevention trial for young children. Prev Med 2007 Jun;44(6):499-503 [FREE Full text] [doi: 10.1016/j.ypmed.2007.03.004] [Medline: 17475318]

35. Boyle RG, Enstad C, Asche SE, Thoele MJ, Sherwood NE. Evaluating strategies and costs to recruit smokeless tobacco users. Addict Behav 2007 Dec;32(12):3088-3092. [doi: 10.1016/j.addbeh.2007.06.005] [Medline: 17602843]

36. Fenner Y, Garland SM, Moore EE, Jayasinghe Y, Fletcher A, Tabrizi SN, et al. Web-based recruiting for health research using a social networking site: an exploratory study. J Med Internet Res 2012 Feb 01;14(1):e20 [FREE Full text] [doi: 10.2196/jmir.1978] [Medline: 22297093]

\title{
Abbreviations \\ ARIA: Accessibility/Remoteness Index in Australia \\ RCT: randomized controlled trial
}

\author{
Edited by G Eysenbach; submitted 14.06.17; peer-reviewed by A Subasinghe, A Cyr, C Lammert; comments to author 20.07.17; \\ revised version received 14.08.17; accepted 21.08.17; published 24.10.17 \\ Please cite as: \\ Burgess JD, Kimble RM, Watt K, Cameron CM \\ The Adoption of Social Media to Recruit Participants for the Cool Runnings Randomized Controlled Trial in Australia \\ JMIR Res Protoc 2017;6(10):e200 \\ URL: http://www.researchprotocols.org/2017/10/e200/ \\ doi: $\underline{10.2196 / \text { resprot. } 8189}$ \\ PMID: 29066427
}

(CJacqueline D Burgess, Roy M Kimble, Kerrianne Watt, Cate M Cameron. Originally published in JMIR Research Protocols (http://www.researchprotocols.org), 24.10.2017. This is an open-access article distributed under the terms of the Creative Commons Attribution License (https://creativecommons.org/licenses/by/4.0/), which permits unrestricted use, distribution, and reproduction in any medium, provided the original work, first published in JMIR Research Protocols, is properly cited. The complete bibliographic information, a link to the original publication on http://www.researchprotocols.org, as well as this copyright and license information must be included. 